\title{
Presentación de quiste de segundo arco branquial como masa orofaríngea: Reporte de un caso
}

\section{Second branchial cleft cyst presenting as oropharyngeal mass: A case report}

\author{
Marcela Veloz T1', Alvaro Pacheco T².
}

\begin{abstract}
RESUMEN
La malformaciones de arcos branquiales constituyen la segunda causa de masa congénita de cabeza y cuello en niños. La presentación clínica depende del arco afectado, siendo las más frecuentes las de segundo arco branquial. Se presenta un caso clínico de un escolar de 7 años que consulta por disfagia lógica, evidenciándose una gran masa orofaríngea posterior a pilar faríngeo posterior izquierdo. El estudio de imágenes con tomografía computarizada (TC) y resonancia magnética (RM) de cuello mostró una lesión quística en relación al pilar faríngeo posterior izquierdo. Se realizó resección transoral de la lesión conservando su pared lateral. El estudio anatomopatológico resultó sugerente de quiste de segundo arco branquial. Se discute la presentación clínica, diagnóstico y alternativas de tratamiento de las anomalías de segundo arco branquial.
\end{abstract}

Palabras clave: Quiste, segundo arco branquial, orofaríngeo.

\begin{abstract}
Branquial cleft malformations are the second cause of congenital mass of the head and neck in children. The clinical presentation depends on the cleft involved; second branchial cleft anomalies are the most common. There is a case of a 7 years old boy with a history of logic dysphagia, fisical examination shows a large oropharyngeal mass located behind the left posterior pillar of the pharynx. The imaging study with computed tomography (CT) and magnetic resonance imaging (MRI) of the neck showed a cystic lesion in relation to the left posterior pillar of the pharynx. Transoral resection of the lesion was performed keeping its lateral wall. Pathologic examination was suggestive of second branchial cyst. Clinical presentation, diagnosis and treatment options of the second branchial cleft anomalies are discussed.
\end{abstract}

Key words: Cyst, second branchial cleft, oropharyngeal.

\footnotetext{
1 Médico Servicio de Otorrinolaringología, Hospital del Salvador.

2 Médico Servicio de Otorrinolaringología, Hospital Luis Calvo Mackenna.
}

Recibido el 19 de marzo de 2015. Aceptado el 30 de abril de 2015. 


\section{INTRODUCCIÓN}

Las malformaciones de arcos branquiales se originan por la obliteración incompleta de los arcos y hendiduras branquiales durante el desarrollo embriológico. Durante la cuarta semana de gestación se identifican cuatro pares de arcos branquiales bien definidos y dos pares de arcos rudimentarios. Estas anomalías constituyen la segunda masa congénita de cabeza y cuello más frecuente en niños alcanzando alrededor de 30\%, después de los quistes del conducto tirogloso; se pueden presentar como quiste, seno o fístula de arco branquial. La presentación clínica depende del arco branquial involucrado ${ }^{1}$.

La anomalía de segundo arco branquial es la más frecuente y se puede encontrar desde la amígdala palatina hasta el borde anterior del músculo esternocleidomastoide ${ }^{1}$. Su forma de presentación más frecuente es como masa cervical lateral; la sensación de cuerpo extraño es un síntoma poco frecuente? ${ }^{2}$.

Presentamos el caso de un quiste de segundo arco branquial de presentación como masa orofaríngea. realizar resonancia magnética (RM) de cuello que reveló una lesión quística lobulada de bordes bien definidos, hiperintensa en secuencia potenciada en T1 y T2, sin cambios en secuencia de saturación grasa ni flair, que mide 2,8 por 5,4 por $3,1 \mathrm{~cm}$ y se ubica en situación submucosa en relación al pilar faríngeo posterior izquierdo, y ocupa la nasofaringe y la región pterigoidea del mismo lado (Figura 1).

Se realiza exploración en pabellón bajo visión endoscópica 0 grados, se observa tejido adenoideo que obstruye ambas coanas. Resto de fosas nasales sin lesiones. Se observa lesión de aspecto quístico detrás de pilar faríngeo posterior (Figura 2) que se punciona bajo visión directa transoral, dando salida a líquido translúcido color verde sin mal olor. Se realiza resección con tijera conservando su pared lateral por encontrarse íntimamente adherida a la mucosa de la pared faríngea. Bajo visión endoscópica se observa tejido adenoideo de tamaño conservado, coanas permeables.

En el estudio anatomopatológico de la pieza operatoria se informa: formación quística revestida

\section{CASO CLíNICO}

Escolar de sexo masculino de 7 años, sin antecedentes mórbidos, que presenta disfagia lógica de cuatro meses de evolución. Consulta en atención primaria, siendo derivado a otorrinolaringología con hipótesis diagnóstica de hiperplasia amigdalina. El paciente evoluciona con dificultad respiratoria nocturna por lo cual consulta en servicio de urgencia siendo derivado a otorrinolaringología por masa orofaríngea en estudio.

Al examen físico se observa gran masa orofaríngea posterior a pilar faríngeo posterior izquierdo, sin signos de dificultad respiratoria en reposo.

En exámenes de laboratorio se encontró hemograma y LDH dentro de rangos normales para la edad. El estudio imagenológico con tomografía computarizada (TC) de cuello mostró una lesión hipodensa de apariencia quística sin realce en su pared, ubicada posterior a amígdala palatina izquierda. Se decide

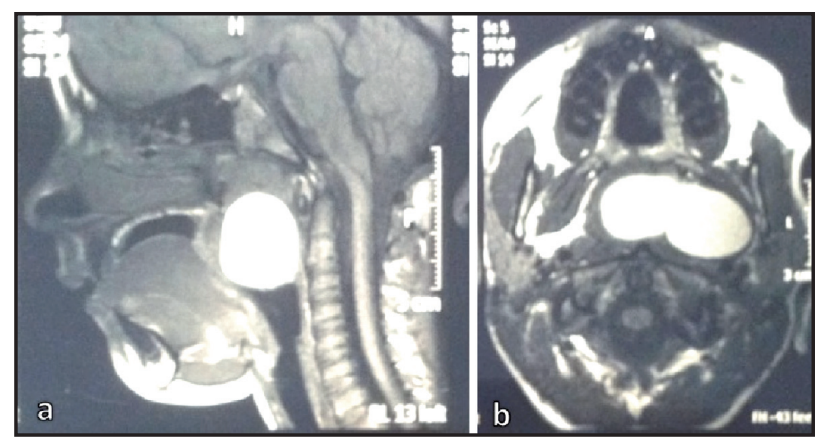

Figura 1. RNM de cuello. 1a, corte sagital de secuencia potenciada en T1; $1 \mathrm{~b}$, corte axial secuencia potenciada en T2.

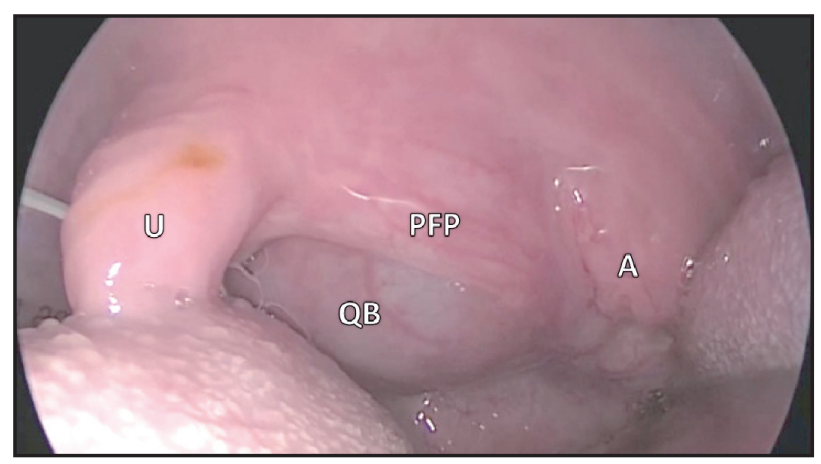

Figura 2. Visión intraoperatoria de la lesión. U, úvula; $Q B$, quiste branquial; PFP, pilar faríngeo posterior izquierdo; A, amígdala palatina izquierda. 
por epitelio de tipo respiratorio de pared fibrosa con infiltrado inflamatorio y focos de hemorragia, rodeada por tejido muscular estriado y en la periferia por mucosa de tipo faríngeo, con epitelio escamoso e intenso infiltrado inflamatorio linfocitario. Incluye también glándulas de tipo mucoso.

Por su localización anatómica y sus características histológicas se concluye quiste de segundo arco branquial izquierdo tipo IV.

\section{DISCUSIÓN}

Dentro de las anomalías de arco branquial, las de segundo arco son las más frecuentes, constituyendo más del $95 \%$ de los casos de estas malformaciones ${ }^{1}$. Las de primer arco branquial son alrededor del $1 \%$ de los casos, y las de tercer y cuarto arco son extremadamente raras ${ }^{13}$.

Las malformaciones de segundo arco pueden presentarse como seno, quiste o fístula, en orden de frecuencia; los quistes se presentan como un aumento de volumen cervical que pueden aumentar rápidamente de tamaño posterior a una infección de la vía aérea superior. También pueden provocar compromiso respiratorio, tortícolis y disfagia. La ubicación más frecuente es en el espacio submandibular adyacente al músculo esternocleidomastoideo.

Se clasifican en cuatro tipos (Bailey I a IV) según su ubicación entre la amígdala palatina y el borde anterior del músculo esternocleidomastoideo y su relación con la vaina carotídea. Este trayecto se puede iniciar en la fosa supratonsilar y es adyacente al nervio hipogloso y glosofaríngeo. La tipo I es superficial al músculo esternocleidomastoideo, sin contactar la vaina carotídea; la tipo II es adyacente a la vaina carotídea; la tipo III se ubica entre la carótida interna y externa y la tipo IV es medial a la vaina carotídea y contacta la pared faríngea a nivel de la fosa tonsilar. Esta última se puede presentar como masa faríngea como en el caso de nuestro paciente.

Los quistes se diagnostican habitualmente durante la tercera y cuarta década de la vida, y pueden aumentar de tamaño posterior a una infección respiratoria; en cambio las fístulas se presentan generalmente en la infancia por el drenaje crónico a nivel del borde anterior del ECM ${ }^{1}$.

En las TC de cuello, las malformaciones de segundo arco muestran una típica apariencia quís- tica, por lo general sin realce de su pared, a no ser que estén infectados. El signo de notch es una proyección focal del quiste entre la bifurcación de la carótida común que se considera patognomónico de un quiste de segundo arco branquial ${ }^{4}$.

Por la naturaleza quística de estas lesiones, en resonancia magnética (RM) se observa una lesión de baja señal en secuencia potenciada en T1 y de alta señal en secuencia potenciada en T2. Las características de la señal pueden variar según el contenido proteináceo del quiste. Los quistes con alto contenido proteináceo presentan aumento de señal en T1 y señal intermedia o baja en T2 ${ }^{5}$.

Histológicamente, estas lesiones pueden estar revestidas por epitelio escamoso estratificado no queratinizado, epitelio columnar ciliado de tipo respiratorio (como en el caso de nuestro paciente) 0 ambos. Se puede encontrar tejido linfoide o infiltrado inflamatorio linfocítico, glándulas salivales y cristales de colesterol en una secreción mucoide fluida ${ }^{1}$.

El tratamiento habitual de estas malformaciones es la extirpación quirúrgica completa de la lesión. El momento adecuado para la cirugía es discutido, algunos recomiendan esperar hasta los dos 0 tres años de vida y otros sugieren realizarla al momento del diagnóstico para disminuir el riesgo de infecciones ${ }^{6}$. Se ha visto que el número de infecciones preoperatorias tiene directa relación con la recurrencia después del tratamiento quirúrgico ${ }^{7}$, que puede ocurrir hasta en $22 \%$ de los pacientes 8 .

El tratamiento quirúrgico tradicional se realiza a través de una incisión cervical lateral abarcando la apertura del seno. La escisión completa de la fístula se puede lograr realizando canulación de ésta. En los últimos años se ha utilizado la cirugía asistida por endoscopía para la resolución de quistes y fístulas de segundo y tercer arco branquial. Se realiza una pequeña incisión en la piel (alrededor de 3 $\mathrm{cm}$ ) hasta localizar la lesión, y luego se continúa la disección asistida por endoscopía sin necesidad de ampliar la incisión. Esta técnica tendría mejor resultado cosmético, menor sangrado y menor lesión de nervios, sin aumentar el riesgo de recurrencia de la lesión después de 1 año de seguimiento $0^{9,10}$.

También se ha utilizado la escleroterapia con OK- 432 (Picibanil), con peores resultados que en otras lesiones quísticas como quistes de conducto tirogloso y linfangiomas. Se ha reportado entre $50 \%$ y $58 \%$ de respuesta en quistes de arco branquial, 
posterior a drenaje por punción e inyección intralesional de OK-432 guiada por ultrasonido. Produce efectos adversos menores tales como fiebre, dolor $y$ aumento de volumen local ${ }^{11-13}$. Se requieren estudios con seguimiento a largo plazo para evaluar la recurrencia después de escleroterapia con 0K-432.

En el caso de quistes de segundo arco branquial de presentación faríngea, se ha propuesto un tratamiento quirúrgico conservador para disminuir el riesgo de complicaciones neurovasculares. Este consiste en la resección de la pared medial del quiste, y marzupialización con sutura reabsorbible de los bordes de la lesión residual a la pared posterior de la farínge y al pilar faríngeo posterior ${ }^{14}$. También se ha estudiado la necesidad de amigdalectomía ipsilateral en pacientes con malformaciones de segundo arco branquial con presencia de fístula, no encontrándose diferencia significativa en la recurrencia si se realiza o no la amigdalectomía ${ }^{15}$.

\section{CONCLUSIÓN}

La presentación de quiste branquial como masa orofaríngea es muy rara, con unos pocos casos reportados en la literatura. Por su localización anatómica y relación con estructuras neurovasculares del cuello, se plantea el tratamiento quirúrgico conservador de estas lesiones y un seguimiento a largo plazo para evaluar su recurrencia.

\section{BIBLIOGRAFÍA}

1. La Riviere CA, Waldhausen JH. Congenital cervical cysts, sinuses, and fistulae in pediatric surgery. The Surgical Clinics of North America 2012; 92(3): 583-97, viii.

2. Aguirre N BG, Araneda F, Celedón $C$, Gac P, Cabané P. Caracterización epidemiológica y clínica de pacientes operados con diagnóstico de quiste branquial. Rev Hosp Clin Univ Chile 2013; 24: 188-92.

3. Geddes G, Butterly MM, Patel SM, Marra S. Pediatric neck masses. Pediatrics in review / American Academy of Pediatrics 2013; 34(3): 115-24; quiz 125.
4. Friedman ER, John SD. Imaging of pediatric neck masses. Radiologic Clinics of North America 2011; 49(4): 617-32, v.

5. Shekdar KV, Mirsky DM, Kazahaya K, Bilaniuk LT. Magnetic resonance imaging of the pediatric neck: an overview. Magnetic Resonance Imaging Clinics of North America 2012; 20(3): 573-603.

6. Goff CJ, Allred C, Glade RS. Current management of congenital branchial cleft cysts, sinuses, and fistulae. Current Opinion in Otolaryngology \& Head and Neck Surgery 2012; 20(6): 533-9.

7. Schroeder JW, JR., Mohyuddin N, Maddalozzo J. Branchial anomalies in the pediatric population. Otolaryngology--head and neck surgery: Official Journal of American Academy of OtolaryngologyHead and Neck Surgery 2007; 137(2): 289-95.

8. ERIKCI V, HOSGOR M. Management of congenital neck lesions in children. Journal of Plastic, Reconstructive \& Aesthetic Surgery: JPRAS 2014; 67(9): e217-222.

9. Chen J, Chen W, Zhang J, et Al. Endoscope-assisted second branchial cleft cyst resection via an incision along skin line on lateral neck. Eur Arch Otorhinolaryngol 2014; 271(10): 2789-93.

10. Barrett G, Toynton S. Endoscopically assisted branchial fistula excision. International Journal of Pediatric Otorhinolaryngology 2013; 77(6): 1048-50.

11. Roh JL, Sung MW, Hyun Kim K, Il Park C. Treatment of branchial cleft cyst with intracystic injection of OK-432. Acta Oto-laryngologica 2006; 126(5): 510-14.

12. KIm MG, KIm SG, Lee JH, Eun YG, Yeo SG. The therapeutic effect of OK-432 (picibanil) sclerotherapy for benign neck cysts. The Laryngoscope 2008; 118(12): 2177-81.

13. Ohta N, Fukase $S$, Suzuki Y, Ishida A, Aoyagl M. Treatments of various otolaryngological cystic diseases by OK-4321: its indications and limitations. The Laryngoscope 2010; 120(11): 2193-6.

14. Díaz-Manzano Ja, Sánchez-Martínez N, IniestaAlcazar J, Medina-Banegas A. Conservative surgical treatment of pharyngeal branchial cyst. Auris, Nasus, Larynx 2008; 35(1): 161-4.

15. Cheng J, Elden L. Management of pediatric second branchial fistulae: is tonsillectomy necessary? International Journal of Pediatric Otorhinolaryngology 2012; 76(11): 1601-3. 